\title{
Hepatic paraganglioma hiding as a slowly growing lesion for 24 years: a diagnostic conundrum
}

\author{
Caroline Annette Erika Bachmeier, ${ }^{1}$ Mazhar Haque, ${ }^{2}$ Helen L Barrett, ${ }^{1}$ Adam Morton ${ }^{1}$
}

${ }^{1}$ Queensland Diabetes and Endocrine Centre, Mater Misericordiae Brisbane Ltd, South Brisbane, Queensland, Australia

${ }^{2}$ Department of

Gastroenterology, Mater Misericordiae Brisbane Ltd, South Brisbane, Queensland, Australia

\section{Correspondence to}

Dr Caroline Annette

Erika Bachmeier,

carolinebachmeier@hotmail.de

Accepted 5 March 2019

\section{DESCRIPTION}

A 69-year-old woman was referred because of a slowly enlarging, asymptomatic liver lesion for which she underwent surveillance imaging. This was originally thought to represent focal nodular hyperplasia. The liver lesion progressed in size from $8.2 \times$ $5.6 \mathrm{~cm}$ on initial imaging to $13.2 \times 6.6 \times 12.7 \mathrm{~cm}$ 24 years later, prompting concerns for a hepatocellular carcinoma (HCC) (figure 1A, CT, and figure 1B, MRI). 2-[Fluorine-18]fluoro-2-deoxy-dglucose positron emission tomography (PET) revealed intensely increased activity associated with the mass and portacaval nodes (figure 1C). $\alpha$-Fetoprotein $(\mathrm{aFP})$ was $1.3 \mu \mathrm{g} / \mathrm{L}$ (normal <12). A presumptive diagnosis of HCC was made and she proceeded to a biopsy of the liver lesion.

Histology from the biopsy of the hepatic lesion revealed a hyalinised stroma and a rich thin-walled vascular network, which divided the cellular tumour up into rounded cellular groups. Immunohistochemistry showed the nests were negative for MelanA, HMB45, MNF116 and AE1/3. The lesions were strongly positive for synaptophysin and chromogranin. S100 staining was consistent with a sustentacular cell network. This confirmed a non-epithelial neuroendocrine lesion consistent with a paraganglioma (PGL). There was no clinical or biochemical evidence of catecholamine excess, and serum chromogranin A was minimally elevated at $176 \mu \mathrm{g} / \mathrm{L}$ (normal <102). Genetic testing for common mutations of hereditary PGL was normal. Scintigraphy demonstrated lack of avidity for metaiodobenzylguanidine and 68Gallium-DOTA-Tyr(3)-Thr(8)-octreotate. Consequently, she was not deemed to be a good candidate for peptide receptor radionuclide treatment. She is now awaiting an extended right hepatectomy.

PGLs are uncommon neuroendocrine tumours usually arising from sympathetic chains or parasympathetic paraganglia. ${ }^{1}$ Hepatic PGLs are rare, with only 12 cases described in the literature. ${ }^{2}$ They are difficult to diagnose correctly as their clinical manifestations and radiological appearance are non-specific. Of the 12 hepatic PGLs previously reported, the primary presumptive diagnosis was HCC in six cases. HCC and PGL are difficult to distinguish radiologically, with similar appearances on CT, MRI and PET scans. aFP is elevated in 80\%-90\% of HCCs greater than $5 \mathrm{~cm}$ in diameter. ${ }^{3}$ The role of a fine needle biopsy could be considered if the
(D) Check for updates

(C) BMJ Publishing Group Limited 2019. No commercial re-use. See rights and permissions. Published by BMJ.

To cite: Bachmeier CAE,
Haque M, Barrett HL,
et al. BMJ Case Rep
2019;12:e228947.
doi:10.1136/bcr-2018-
228947
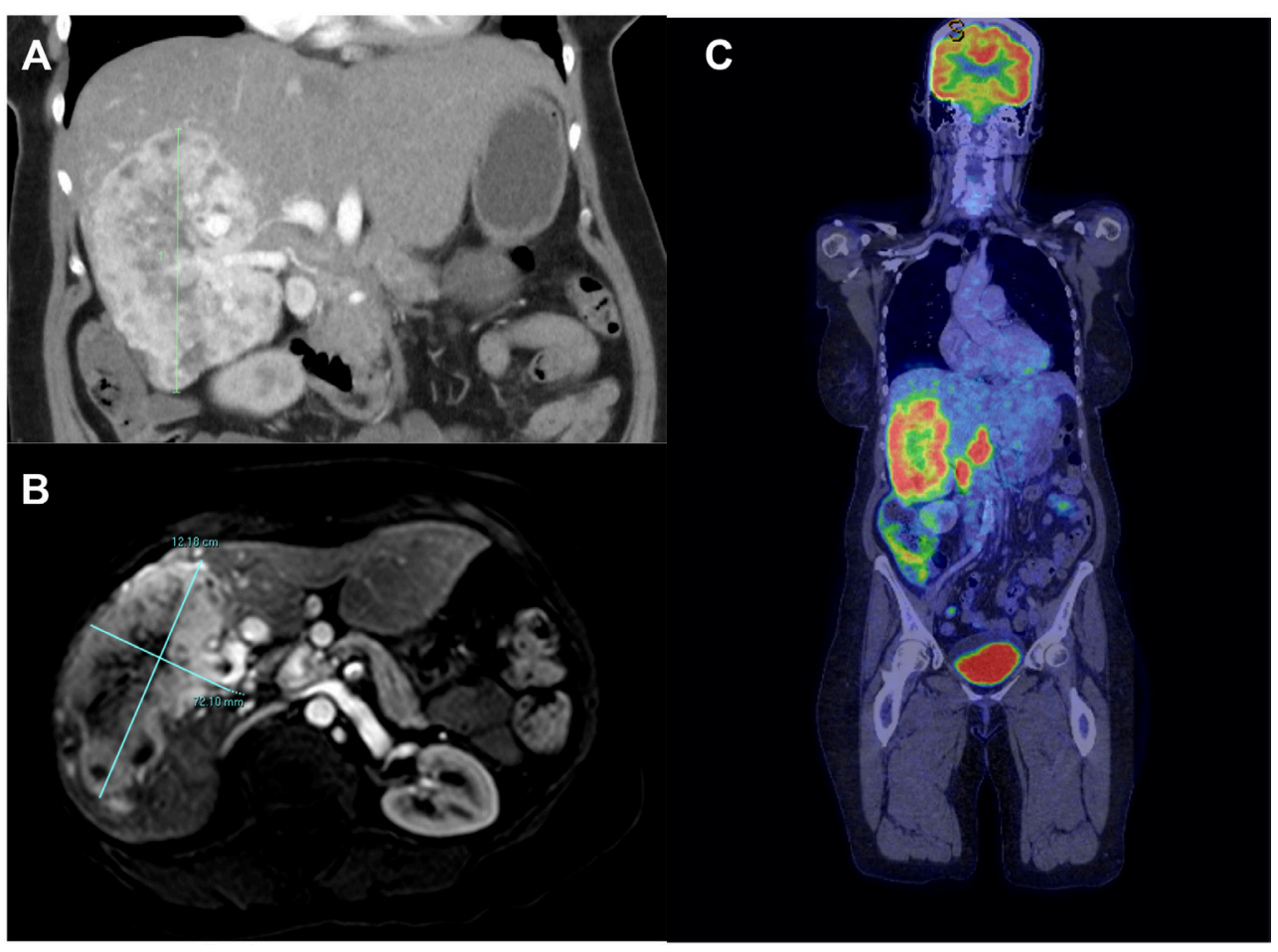

Figure 1 (A) CT shows a large right-sided liver lesion. (B) MRI shows a large right-sided liver lesion. (C) 2[Fluorine-18]fluoro-2-deoxy-d-glucose positron emission tomography showing intense avidity in a large liver lesion and portacaval lymph nodes. 
diagnosis is unclear after imaging studies. However, there is a high rate of non-diagnostic biopsies, an elevated rate of false-positive results for HCC and an associated risk of bleeding. ${ }^{4}$ Furthermore, seeding needs to be taken into account with one meta-analysis showing an incidence as high as $2.7 \% .^{6}$ Due to the high risk of bleeding and catecholamine crisis, a lesion should not be biopsied if a PGL is suspected. ${ }^{7}$

In conclusion, hepatic PGL should be considered in the differential diagnosis of HCC with large hepatic tumours where aFP is normal.

\section{Learning points}

- Paragangliomas (PGLs) should be considered as a differential diagnosis in liver lesions.

- Hepatic PGLs should be considered with large hepatic tumours where $\alpha$-fetoprotein is normal.

- Fine needle biopsy of a liver lesion can be considered if the diagnosis/aetiology is unclear after obtaining imaging studies. However, this method should be used only if this is likely to affect or change the patient's management and under consideration of possible associated risks.

Acknowledgements We would like to acknowledge the work of Dr Rohan Lourie, who performed the histopathology work-up for this case. We would also like to acknowledge all members from the involved gastroenterology and oncology teams.
Contributors All authors have significantly contributed to the care of this patient and have contributed to the writing and editing of this manuscript. HLB and AM have reviewed the patient in their role as Endocrinology consultants and $\mathrm{MH}$ in his role as the Gastroenterologist. CAEB has reviewed the patient in her role as the Endocrinology trainee. All four authors have had input in writing and editing this article.

Funding The authors have not declared a specific grant for this research from any funding agency in the public, commercial or not-for-profit sectors.

Competing interests None declared.

Patient consent for publication Not required.

Provenance and peer review Not commissioned; externally peer reviewed.

\section{REFERENCES}

1 Young WF. Paragangliomas: clinical overview. Ann N Y Acad Sci 2006;1073:21-9.

2 Liao W, Ding ZY, Zhang B, et al. Primary functioning hepatic paraganglioma mimicking hepatocellular carcinoma: a case report and literature review. Medicine 2018;97:e0293.

3 Nomura F, Ohnishi K, Tanabe Y. Clinical features and prognosis of hepatocellular carcinoma with reference to serum alpha-fetoprotein levels. Analysis of 606 patients. Cancer 1989;64:1700-7.

4 Venkatesh S, Chandan V, Roberts LR. Liver Masses: A clinical, radiological and pathological perspective for: perspectives in clinical gastroenterology and hepatology. Clin Gastroenterol Hepatol 2014;12:1414-29.

5 Assy N, Nasser G, Djibre A, et al. Characteristics of common solid liver lesions and recommendations for diagnostic workup. World J Gastroenterol 2009;15:3217-27.

6 Silva MA, Hegab B, Hyde C, et al. Needle track seeding following biopsy of liver lesions in the diagnosis of hepatocellular cancer: a systematic review and meta-analysis. Gut 2008:57:1592-6.

7 Vanderveen KA, Thompson SM, Callstrom MR, et al. Biopsy of pheochromocytomas and paragangliomas: potential for disaster. Surgery 2009;146:1158-66.

Copyright 2019 BMJ Publishing Group. All rights reserved. For permission to reuse any of this content visit

https://www.bmj.com/company/products-services/rights-and-licensing/permissions/

BMJ Case Report Fellows may re-use this article for personal use and teaching without any further permission.

Become a Fellow of BMJ Case Reports today and you can:

- Submit as many cases as you like

- Enjoy fast sympathetic peer review and rapid publication of accepted articles

- Access all the published articles

Re-use any of the published material for personal use and teaching without further permission

For information on Institutional Fellowships contact consortiasales@bmjgroup.com

Visit casereports.bmj.com for more articles like this and to become a Fellow 